Marcelo da Silva Carneiro*

\title{
1 Macabeus: memórias épicas de uma guerrilha santa
}

\begin{abstract}
Resumo: Esse artigo apresenta o livro de 1 Macabeus como uma história de luta e esperança, em busca de liberdade e da retomada da terra, mostrando seu contexto e a importância desse momento histórico para a formação da identidade judaica. Por isso, é um livro inspirador de lutas pela liberdade e a vida, resistindo à opressão e às injustiças.
\end{abstract}

Palavras-chave: Macabeus, Helenismo, Asmoneus, Liberdade, Revolta dos Macabeus.

\begin{abstract}
This article presents the Book of 1 Maccabee as a fight and hope story, in the quest of freedom and the self-rule, shows its context and the significance of this historic moment for the Jewish identity formation. Therefore, it's an inspiring book for freedom and life, as resistance to oppression and injustices. Keywords: Maccabee, Hellenism, Hasmoneans, Freedom, War of the Maccabees.
\end{abstract}

\section{Para começo de conversa}

Ler o Livro dos Macabeus é um desafio diante do apelo que muitos outros livros da Bíblia têm sobre nós: ele não contém doutrina ou palavras confortadoras, nem personagens muito conhecidos. Mas em suas páginas, no meio de sua narrativa, percebemos tanto um quanto o outro. Vemos na coragem dos Macabeus o eco dos heróis antigos como Moisés e Davi, que alicerçaram a fé que sustentou a revolta popular. Por isso, vale a pena conhecer essa história e entender as motivações, o processo e saber mais desse momento que foi decisivo para Israel mostrar sua cara diante das nações.

Nosso artigo está construído em três momentos: no primeiro vamos passear pela narrativa, como está construída. Vale a pena pegar

* $\quad$ Doutor em Ciências da Religião pela UMESP. Mestre em Teologia pela PUC-RJ. Teólogo Metodista. 
a Bíblia e ler junto, para ver nas próprias palavras dela o que vai ser descrito aqui. No segundo momento, após conhecer a história, vamos ver os bastidores: analisar sua estrutura literária, origem, e contexto sócio histórico que fundamentou o livro. Finalmente, no terceiro momento, vamos pensar a mensagem de 1 Macabeus, as motivações teológicas e ideológicas, e o que esse livrinho nos deixa como ensinamento e motivação para a nossa luta de hoje. E que luta!

\section{A narrativa do livro}

O livro conta a história da família de Matitias e seus filhos Judas, Jônatas e Simão, quando se rebelaram contra o domínio Selêucida, no período de Antíoco IV Epífanes. A narrativa toma posição a respeito do domínio helenista sobre a Palestina, a começar pelas conquistas de Alexandre o Grande

O início da narrativa dá o tom do livro no geral ao descrever as conquistas de Alexandre o Grande e seu projeto imperialista em três dimensões:

1. Na força bélica: "empreendeu numerosos combates, ocupou fortalezas, assassinou reis, (...) saqueou inumeráveis nações" (1,2-3a);

2. Na arrogância de Alexandre, após a pacificação por meio da força: "quando a terra ficou em paz sob o seu comando, ele se exaltou e se encheu de orgulho" (1,3b);

3. Na sucessão de opressores: "ao morrer Alexandre, todos cingiram a coroa real, e depois os filhos deles durante muitos anos, multiplicando as desgraças do mundo" $(1,9)$.

Essa descrição expressa críticas de quem foi dominado pelos gregos cuja marca era: o expansionismo bélico, a arrogância dos governantes que se autodivinizavam, como era costume no ambiente helênico, e a continuidade da opressão por parte dos sucessores desses governantes. Tudo isso era considerado como a raiz das "desgraças do mundo". Além disso, o fato de Alexandre ter estabelecido, ou mesmo mantido a prática persa de cobrança de tributos das nações dominadas fazia com que a dominação helênica fosse considerada um mal no mundo. Depois veremos melhor o porquê dessa visão tão negativa. Por outro lado, essa introdução aponta para os riscos que a liderança judaica terá que enfrentar quando estiver no lugar dos estrangeiros, e que a narrativa posterior mostrará se foram bem sucedidos em evitá-los ou caíram na mesma armadilha. 
A partir de 1,10, a narrativa destaca a pessoa de Antíoco Epífanes, chamado de "rebento perverso". Esse personagem é apresentado de tal maneira que se torna o principal responsável pela revolta que se segue, liderada por Matitias. As ações de Antíoco agradaram alguns mas deixa a maioria dos israelitas contrariada: promove jogos olímpicos nas terras de Israel, praticados por homens completamente nus, e alguns chegam a reverter a circuncisão por causa disso. 0 narrador considera isso como um desvio muito grave: "e então, acomodando-se aos usos pagãos, construíram um ginásio em Jerusalém, dissimulando a circuncisão, apostataram da aliança santa, tornaram-se parentes dos pagãos e se venderam para fazer o mal." $(1,14,15)$

A partir daí o livro se desdobra em quatro momentos:

1. A revolta de Matitias e seus filhos (1-2)

2. A liderança de Judas Macabeus $(3,1-9,22)$

3. A liderança de Jônatas $(9,23-12,52)$

4. A liderança de Simão $(12,53-16,22)$

A forma como a narrativa foi construída permite comparar a trajetória dos irmãos: levantam-se com força e coragem, defendendo a fé contra a dominação helênica e seu projeto de uma sociedade aberta (e consequentemente uma religião com preceitos menos rígidos). Os líderes conseguem grandes vitórias, inclusive contra grupos internos. Após as primeiras vitórias, eles se rendem a esquemas políticos com o objetivo de consolidar seu poder, numa tentativa de tornarem-se grandes. E aí está o fator de queda de todos eles, que os leva a derrotas e à morte.

A narrativa de Judas é a mais longa e elaborada: a campanha militar dele pode ser dividida de forma quiástica, ou acróstica, como sugere Sandro Galazzi: ${ }^{1}$

A - JUDAS O COMANDANTE $(3,1-4,35)$

B - O templo libertado (4,36-61) C - JUDAS O PASTOR (5)

B' - A morte de Antíoco (6,1-17)

A' - JUDAS O CHEFE $(6,18-9,22)$

$\mathrm{Na}$ campanha militar de Judas são retratadas oito batalhas, das quais em cinco ele sai vitorioso e em três é derrotado. A última foi contra o general Báquides, com um Judas desanimado, muitas deserções, e apenas 800 homens contra "vinte mil soldados da infantaria e dois mil cavaleiros." $(9,4 b)$ Diante do conselho de fugir para poupar a própria vida, Judas res-

GALAZZI, Sandro. Primeiro Livro dos Macabeus, p.32. 
ponde: "Nada de fugir diante do inimigo! Se houver chegado a nossa hora, morramos valentemente por nossos compatriotas, sem deixar uma mancha em nossa fama." $(9,10)$ Assim o grupo de Judas se lança numa batalha final, que dura bastante, ao fim da qual muitos morrem, inclusive Judas.

A partir daí começa o período da liderança de Jônatas que se levanta com a terra abatida, necessitando mais ainda de uma ação libertadora. Ele combate Báquides e Alcimo, consegue derrotá-los e impor condições de paz, e assim "a espada descansou em Israel" (9,73a). Depois disso Jônatas vai atrás de alianças diplomáticas vantagens (inclusive com Roma), que terminam por corromper sua liderança e enfraquecê-la, até que ele é sequestrado por Trifão, conselheiro de Antíoco, filho de Balas, e acaba morto.

Com a morte de Jônatas, seu irmão Simão assume o comando do exército judeu, para impedir a invasão de Trifão. Ele consegue superar os inimigos e a narrativa demonstra que a liderança de Simão reafirma a liberdade: "Israel sacudiu de si o jugo estrangeiro (...), e começaram a datar assim os documentos e contratos: "Ano primeiro de Simão o Grande, sumo sacerdote, general e chefe dos judeus'." (13,41-42) Com isso o texto aponta para uma situação que a princípio é boa, mas que depois se tornará penosa para o povo: uma mesma pessoa acumulando a liderança religiosa, militar e de governo. Também Simão procura apoio estrangeiro por via diplomática, tanto com Roma quanto com outros grupos, e acaba sendo morto numa armadilha pelas mãos de Ptolomeu, um idumeu ligado a ele por razões políticas.

A fórmula final do livro deixa em aberto a situação da Judeia, mas dá a entender que os momentos mais gloriosos relacionados à revolta macabaica - com os irmãos Judas, Jônatas e Simão - e a libertação do jugo estrangeiro já passaram e que o futuro não teria o mesmo esplendor.

\section{A história por trás do livro: intertextualidades e contexto}

O livro dos Macabeus deve ter surgido entre 104 e 63 a.C. Essa datação se justifica pelos seguintes aspectos: João Hircano morreu em 104, e o livro encerra falando do período de seu reinado, sem dar-lhe qualquer destaque; de outra parte, as diversas citações a respeito de Roma como possível aliado indica um período anterior à dominação romana, que aconteceu a partir de 63 a.C., data em que Pompeu conquistou a Palestina. A ausência de Macabeus no cânon judaico pode ter sido motivada pelo fato do livro ter surgido no período asmoneu, grupo que depois representou para os judeus ortodoxos um retrocesso no processo de autonomia e liberdade dos judeus. No entanto, aparecem em todas as liturgias das igrejas oci- 
dentais e orientais, tendo sido colocado no cânon do Concílio de Trento. Já o protestantismo deixou-o de fora, pelo debate em relação ao cânon original. Os manuscritos testemunham o texto em grego, e já não existem mais cópias do original hebraico, desde Jerônimo, em 400 d.C.; por isso, Macabeus é associado à Septuaginta, e ignorado no cânon judaico oficial.

Do ponto de vista literário, o texto de 1 Macabeus faz eco aos livros de Josué, Samuel e Reis, com ênfase nas tramas políticas e disputas territoriais. Inicia com a expressão "kai egéneto", tradução do hebraico "wayehi" (e aconteceu), como em Js 1,1;2Sm 1,1. E termina com uma fórmula muito repetida nos livros dos Reis e Crônicas: "Para outros dados sobre João e as façanhas militares que realizou, as muralhas que construiu e seus empreendimentos, vejam-se os anais de seu pontificado, a partir da data de sua consagração como sumo sacerdote, sucessor de seu pai." (1Mc 16,23-24) Cenas de batalha, às vezes com riquezas de detalhes, reforçam a imagem de um período violento e com muitos conflitos. Pode-se dizer que ele segue a lógica da historiografia deuteronomista, em que o centro da fé é a vivência da Lei na terra de Israel, num projeto de liberdade, sem a opressão das cidades que cobram tributos e com partilha igualitária. Esse projeto remonta ao Êxodo e a conquista da terra por Josué, daí a semelhança na estrutura literária.

Outra característica literária marcante de 1 Macabeus são as canções e poesias, pontuando os momentos altos e baixos no curso da história. Há desde cânticos de lamentação $(1,37-40 ; 2,10-12)$, passando por testamento solene (2,49b-68), até cânticos de homenagem (3,3-9; 14,4-15). Somente na parte de Jônatas não há nenhuma canção ou poesia, cuja explicação é apontada por Erich Zenger na forma de pergunta: "será que nessa reticência do autor se refletem reservas de outros grupos judaicos (especialmente dos essênios) diante do fato de que Jônatan (sic), cuja habilidade militar e diplomática ninguém contestava, assumiu a dignidade de sumo sacerdote da mão de um soberano sírio de legitimidade questionável?"² Seja como for, essa técnica narrativa aproxima 1 Macabeus da tradição hagiográfica de 1/2 Sm e 1/2 Rs. Além disso, há referência a cartas escritas entre reis estrangeiros e líderes judeus, e supostamente transcritas na íntegra: Uma cópia em tabuinhas de bronze, da parte do senado romano aos judeus de Jerusalém, "como documento fidedigno do pacto de paz e mútua defesa" (8,23-32); troca de correspondência entre Demétrio e Jônatas, e entre este e Alexandre Balas, num processo de intrigas políticas (10,18-20; 18,25b-45); também de Demétrio II a Jônatas (11,30-37); de Jônatas aos

ZENGER, Erich. Introdução ao Antigo Testamento, p.271. 
espartanos, considerados irmãos pelos judeus (12,5-23); de Demétrio para Simão (13,36-40); e dos espartanos a Simão (14,20b-23); e outras para Simão. Assim, o autor deseja dar autoridade ao escrito, associando-o a documentos oficiais.

Diversas passagens do Antigo Testamento são citadas indiretamente. No discurso de despedida de Matitias, organizado de forma programática em relação ao livro, são destacados os nomes de Abraão, José, Finéias, Josué, Calebe, Davi, Elias, Ananias, Azarias e Misael, e por fim Daniel. Em 3,18, Judas incentiva seus guerreiros com uma frase que lembra a de Jônatas em 1Sm 14,6: "Não é difícil alguns poucos envolverem muitos, pois a Deus custa a mesma coisa salvar com muitos ou com poucos;". Em 3,43, fala-se em "restaurar ruínas", lembrando Is 58,12 e Am 9,11. Ainda em 3,52, uma oração lembra o Salmo 83, quando afirma: "Vês que os pagãos se reuniram para nos exterminar. Conheces seus planos contra nós". Uma referência a Ez 38, 16.23; 39,7.23.28 aparece em outro discurso de Judas, recordando as vitórias contra o Faraó, em 4,8-11. Na grande repatriação de $5.45 \mathrm{ss}$, há referência indireta a várias profecias: Is 60; 27,12-13; 35,10; Sf 3,20.

Nesse sentido, ele pretende ser um relato do cumprimento de profecias escatológicas, que falam de paz e prosperidade para Israel e os justos cumpridores da Lei. Assim, as ações de seus filhos devem ser compreendidas como atos libertadores a favor de Israel, em cumprimento à Lei de Deus. Por isso o narrador toma posição: ele está claramente ao lado dos conservadores e critica abertamente os helenistas, chamando-os de "apóstatas" (gr. paránomoi), não só por causa da quebra da Lei, mas pelo desejo deles de se aproximar das outras nações, em busca de riqueza e poder. Mesmo assim, apresenta um quadro bastante realista do período entre os anos 175-161 a.C., mesmo levando em conta essa parcialidade.

Não há nenhuma intervenção divina direta, apenas a devoção dos macabeus e seus aliados, que a todo momento rezam por ajuda e pedem força a Deus, ou cantam louvores a Ele $(2,7-9 ; 3,22 ; 3,50-53$; 4,24-25; 4,30-33; 7,37-38). Não há anjos nem quaisquer elementos típicos da apocalíptica, o que coloca esse texto num ambiente escribal mais austero e voltado para a prática da lei e a preservação da identidade e território israelitas. Destaque negativo é a quase absoluta ausência de mulheres na trama; o desenrolar da história é construída apenas com personagens masculinos. Com exceção da filha de Ptolomeu, que é dada como esposa a Demétrio, num casamento político, as mulheres só constam indiretamente, pela referência aos filhos dos personagens. Considerando a tradição hagiográfica 
dos israelitas é um aspecto bastante relevante, pois mostra um rigoroso esquema patriarcal - e quem sabe misógino - que nega às mulheres espaço na memória dos acontecimentos.

Uma das ações mais importantes de Judas foi a de purificar o templo, profanado por Antíoco, que o saqueou (1,21-24) e permitiu sacrifícios ao Zeus Olímpico (1,54-61). Na consagração todos os elementos internos foram reconstruídos e houve oito dias de festa, começando no dia 25 de dezembro (que deu origem à festa judaica de Hanuká, celebrada todos os anos neste mesmo período).

Qual a identidade do grupo que fez a revolta dentro da estrutura social de Israel? Além dos macabeus, outros grupos são citados no texto, como parte dos revoltosos: os assideus (gr. Asidaiôn) ou "piedosos", que se organizavam em uma sinagoga própria $(2,42)$; os que fugiam da desgraça $(2,43)$, e os sacerdotes sem defeito, observantes da Lei $(4,42)$.

Os macabeus, cujos nomes predominam no livro a ponto da tradição posterior o denominar assim são homens do interior, de Modin. Identificados com a linhagem sacerdotal de Joiarib, faziam parte dos sacerdotes que atuavam no campo, longe da pompa do templo, que assistiam ao povo e percebiam seu sofrimento em função dos altos tributos que lhes eram impostos. O povo simples da terra vivia na esperança antiga, de que sua parte seria para o sustento da família e para abençoar o forasteiro de passagem. Entretanto, essa esperança lhes era negada, e por causa do peso da opressão gemiam e ansiavam por liberdade. Matitias e seus filhos foram, na verdade, porta-vozes dos anseios populares de liberdade e justiça.

Os assideus eram na verdade um movimento religioso presente tanto na cidade como no campo, entre os ricos e os pobres, de pessoas apegadas à Lei e contrárias às mudanças que os selêucidas e os helenistas faziam na terra de Israel. Os que fugiam da desgraça são diversas pessoas e famílias que sofreram com a opressão, a violência e cansados da vida que estavam levando se juntaram aos revoltosos. Finalmente, os sacerdotes sem defeito eram sacerdotes que estavam em Jerusalém, mas não aceitaram a helenização da cidade, especialmente depois da traição de Jasão que culminou com a morte do sacerdote Onias, retratada em $2 \mathrm{Mc} 4$. Aliás, enquanto 1 Macabeus parece ter sido redigida por alguém ligado aos macabeus, 2 Macabeus tem por trás de seu texto os assideus e sacerdotes que participaram da revolta, por isso os textos correm em paralelo, mas com diferenças nas suas versões.

A revolta teve, como já foi dito, um caráter libertador, contra a dominação estrangeira perpetrada pelos gregos e apoiada por parte da elite 
judaica, que se beneficiava com essa situação. Pedro Lima Vasconcellos sugere o seguinte esquema para compreender o processo: ${ }^{3}$

\begin{tabular}{|c|c|}
\hline Os gregos querem: & Os judeus resistem: \\
\hline $\begin{array}{l}\text { - Transformar a Palestina em "terra } \\
\text { do rei"; } \\
\text { - Arrecadar dinheiro para pagar a } \\
\text { dívida externa; } \\
\text { - Incrementar o comércio lucrativos } \\
\text { de escravos; } \\
\text { - Acabar com o Etnos e transformá- } \\
\text { la em pólis; } \\
\text { - Tributar o templo; } \\
\text { - Leiloar, ano após ano, o sumo } \\
\text { sacerdócio; } \\
\text { - Ouebrar a resistência do povo. }\end{array}$ & 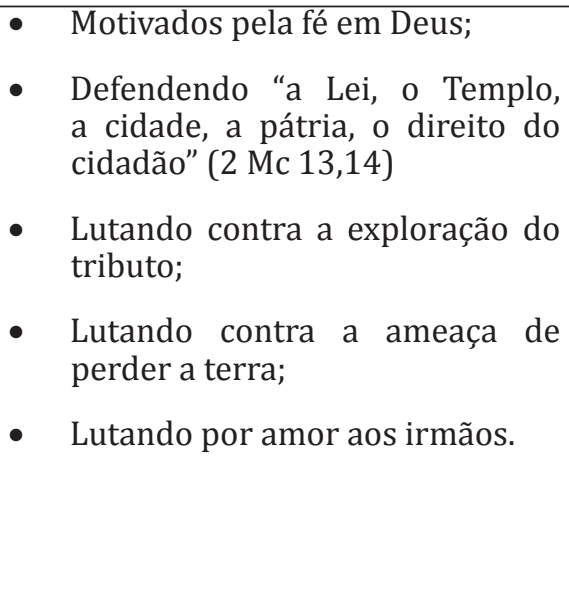 \\
\hline
\end{tabular}

\section{A mensagem de 1 Macabeus: entre a identidade e a luta pela liberdade}

Ao mencionar as grandes vitórias do passado, bem como colocar as diversas orações a Deus, pedindo socorro ou clamando por justiça, o livro dos Macabeus coloca a revolta como ação libertadora de Deus na vida do povo. Os líderes são, desse modo, representantes de Deus para abençoar o povo com liberdade e paz, conseguida, no entanto, com o derramamento de sangue. Não é por acaso que eles acabaram por assumir o manto de sumo sacerdotes, ironicamente aproximando-se da forma como os reis helênicos eram compreendidos. Por isso mesmo o livro, que não esconde a simpatia pelos asmoneus, tem a coragem de fazer autocrítica do próprio movimento de libertação. Nesse processo de autocrítica, três aspectos podem ser destacados:

(1) o perigo da soberba e a tentação de poder. A narrativa mostra bem claramente que os irmãos começam sua decadência pelo fato de buscarem alianças com estrangeiros, em vez de confiar na proteção divina. Isso aponta para o outro lado da questão: o desejo de serem reconhecidos no plano internacional como grandes líderes, e desse modo imortalizarem o próprio nome.

VASCONCELLOS, Pedro Lima. Como Ler os Livros dos Macabeus, p.20. 
Esse é um alerta para os leitores, seja de que classe forem: melhor que ter o nome reconhecido pelos demais, é confiar no Nome santo.

(2) a necessária reação violenta diante da opressão. A história de Israel está marcada pela violência. No entanto, os macabeus iniciam seu processo de violência como reação ao domínio opressor e violento dos estrangeiros e "apóstatas". No início do processo, um episódio marca de que maneira o processo irá se dar: pelo fato dos judeus guardarem o sábado, são mortos pelos soldados de Antíoco. Os que não morrem decidem quebrar o sábado para garantir a vida, caso contrário, morrerão, ou como afirmam: "Se todos nós fizermos como nossos irmãos, não lutando contra os pagãos pela vida e por nossa Lei, em breve eles vão nos eliminar do país." $(2,40)$. Se os outros foram mártires da causa, está bem; mas é necessário que o povo viva, e nesse caso a vida se põe acima da Lei. Bela reflexão em meio a todo o processo de luta, que depois será levada adiante por Jesus, em suas controvérsias com os fariseus.

(3) a busca pela pureza como marca da identidade judaica. Se o sábado teve que ser quebrado para manter a vida, os demais aspectos da Lei puderam ser seguidos fielmente. A circuncisão, os sacrifícios, os alimentos devidos e a guarda das festas - e até mesmo do sábado - voltaram a ser parte integrante da vida dos judeus na terra de Israel. E isso significa identidade, marca do povo separado para viver naquele lugar, no projeto de liberdade e justiça iniciado no Êxodo, mas cujas raízes são anteriores, no patriarca Abraão. Autores como Jacob Neusner, profundos estudiosos da cultura judaica, reconhecem que nesses fatores está a identidade do povo judeu, de tal maneira que, mesmo depois que o templo foi destruído, se mantiveram como nação, e não se dispersaram, desaparecendo por completo.

Assim, 1 Macabeus nos deixa o desafio de não esmorecer na luta pelo povo, pelas coisas justas, pela verdadeira liberdade que teimosamente se mantém no horizonte da nossa fé. À luz dos Evangelhos já não cabe responder com violência física, mas a exemplo do espírito dos macabeus, resistir com coragem e força. Como afirmou Judas Macabeus: "Restauremos a ruína de nosso povo! Lutemos por nosso povo...!" 


\section{Referências}

BICKERMAN, Elias. From Ezra to the Last of the Maccabees. Foundations of Postbiblical Judaism. New York: Schocken Books. 1975.

GALAZZI, Sandro; RUBEAUX, Francisco. Primeiro livro dos Macabeus. Comentário Bíblico Latino-Americano - Antigo Testamento. São Paulo: Fonte Editorial, 2013.

IGLESIAS, Manuel. “1 Macabeus”. In: SCHÖKEL, Luís Alonso (Ed.). Bíblia do Peregrino. São Paulo: Paulus, 1997.

OTZEN, Benedikt. 0 judaísmo na Antigüidade. A história política e as correntes religiosas de Alexandre Magno até o imperador Adriano. São Paulo: Paulinas, 2003.

VASCONCELLOS, Pedro; SILVA, Rafael Rodrigues da. Como ler os livros dos Macabeus. Memórias da Guerra: o Livro das Batalhas e o Livro dos Testemunhos. São Paulo: Paulus, 2004.

ZENGER, Erich (ed.). Introdução ao Antigo Testamento. São Paulo: Edições Loyola, 2003.

Marcelo da Silva Carneiro Rua Felipe Sabbag, n. 47 - Ap. 04 Centro Ribeirão Pires - SP CEP: 09400-130 - Brasil E-mail: prmscarneiro@yahoo.com.br 